\title{
FRACTURES OF THE SHAFT OF THE HUMERUS
}

\author{
L. Klenerman, London, England
}

This paper reviews a series of fractures of the shaft of the humerus with particular reference to deformity after conventional methods of immobilisation and to the disability that may result from angulation at the fracture site.

Reviews by Ghormley and Mroz (1935), O'Shea (1936), Eve and Daniel (1941), Stewart and Hundley (1955), Kennedy and Wyatt (1957), and the Scientific Research Committee Pennsylvania Orthopaedic Society (1959) have dealt with the treatment of fractures of the shaft of the humerus by hanging plasters, shoulder spicas, abduction splints, Thomas's arm splints and Velpeau bandages. I have been unable to find a report of a series treated by the relatively simple splintage of a U-shaped plaster and a collar-and-cuff sling, or by a sling alone.

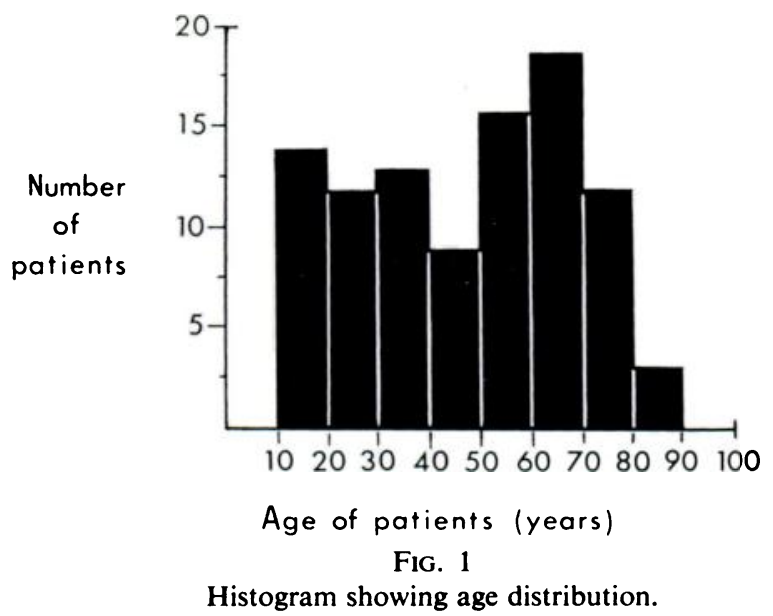

CLINICAL MATERIAL

There were ninety-eight patients with fractures of the shaft of the humerus, defined as that part below the surgical neck and above the level of the epicondyles. Injuries in children and pathological fractures were excluded. Fifty-five patients were men and forty-three were women. Most of the patients were treated at the Middlesex Hospital and the London Hospital; a third smaller group came from King Edward VII Memorial Hospital, Ealing. The age distribution is shown in Figure 1.

\section{METHOD OF STUDY}

The notes and radiographs of the patients were reviewed. Letters were written to all the patients and thirty-two patients were interviewed and questioned regarding any disability in relation to the fracture. Examination was carried out with particular reference to deformity and the range of movements at the elbow and shoulder, and radiographs were taken. The time that had elapsed since injury ranged from four months to nine and a half years.

\section{VARIETIES OF FRACTURE}

In seventy-three patients the fractured humerus was the only injury, but twenty-five had other injuries as well. Five had injuries to the same limb which made treatment more difficult: namely fractures of the olecranon, fracture of the clavicle, posterior dislocation of the shoulder with fracture of the greater tuberosity of the humerus, dislocation of the elbow, and compound 
Monteggia fracture-dislocation. The patient with fracture of the clavicle had the humeral fracture stabilised by the insertion of a four-hole plate and screws. The patient with the Monteggia fracture-dislocation, after wound excision and skin grafting, was treated conservatively until the local sepsis had subsided, but the humeral fracture failed to unite and required bone grafting. In the remainder of these five patients the humeral fracture was treated conservatively.

Level of fracture - The fractures were subdivided according to their level in the shaft, as shown in Table I. The middle third of the shaft was by far the commonest site.

Type of fracture-The type of fracture, whether transverse, oblique or spiral, and the association of a butterfly fragment as distinct from a minor degree of comminution was recorded (Table II). The common occurrence of spiral fractures in patients over fifty may be related to the brittleness of the bone.

TABLE I

LeVel of Fracture

\begin{tabular}{|c|c|c|c|}
\hline \multirow{2}{*}{\multicolumn{3}{|c|}{$\begin{array}{l}\text { Uppermost third of shaft } \\
\text { Junction of middle and uppermost thirds }\end{array}$}} & $22 *$ \\
\hline & & & 4 \\
\hline Middle third of shaft & & & 44 \\
\hline Junction of middle and & est thirds & & $12^{*}$ \\
\hline Lowest third of shaft & . & . & 17 \\
\hline Total & . & & 99 \\
\hline
\end{tabular}

* One patient had a double fracture.

TABLE II

Pattern of Fracture

\begin{tabular}{|l|c|c|c|}
\hline & $\begin{array}{c}\text { Total number } \\
\text { of patients }\end{array}$ & $\begin{array}{c}\text { Patients over } \\
\text { 50 years }\end{array}$ & $\begin{array}{c}\text { Butterfy } \\
\text { fragments }\end{array}$ \\
\cline { 1 - 3 } Transverse fracture & 33 & 10 & 3 \\
Oblique fracture & 26 & 14 & 5 \\
Spiral fracture & 39 & 26 & 8 \\
\hline
\end{tabular}

\section{TREATMENT}

Eighty-seven patients were treated conservatively. In most, a U-shaped plaster and a collar-and-cuff sling were applied, generally without anaesthesia (Fig. 2). Eight patients were treated by a collar-and-cuff sling alone, two by a shoulder spica and two by a hanging plaster. In eleven patients internal fixation was carried out because of multiple injuries, distraction of the fragments or difficulty in maintaining adequate alignment.

Compound fractures-Six fractures were compound. One patient developed infection with delayed union and bone grafting was necessary. Of the remaining five patients two had intramedullary fixation of the fracture after the primary wound had healed, and three, after wound excision, were treated by closed methods and the fractures united satisfactorily.

Radial nerve palsy-Ten patients had a radial nerve palsy. All were recognised at the time of injury and none occurred later. In seven there was gradual recovery until full motor power returned, but in two failure to recover was considered an indication for exploration. One 
nerve was found to be divided, and the other recovered after it had been mobilised and removed from a bed of callus and placed in healthy tissue. Two patients with normal motor function had hypoaesthesia in the distribution of sensory branches of the radial nerve. One involved the lateral cutaneous nerve of the forearm, and the other the superficial radial nerve. One patient failed to attend before completion of this treatment.

The patients with nerve lesions were grouped according to the level of the fracture (Table III). Their ages ranged between the thirties and the seventies.

The relationship of the level of fracture to nerve palsy corresponds with that described by Scudder (1915) and Cubbins and Scuderi (1933). The four nerve injuries in association with fractures at the junction of middle and lowest thirds of the shaft may well have occurred as the radial nerve has least mobility at this point, where it pierces the lateral intermuscular septum (Holstein and Lewis 1963). The

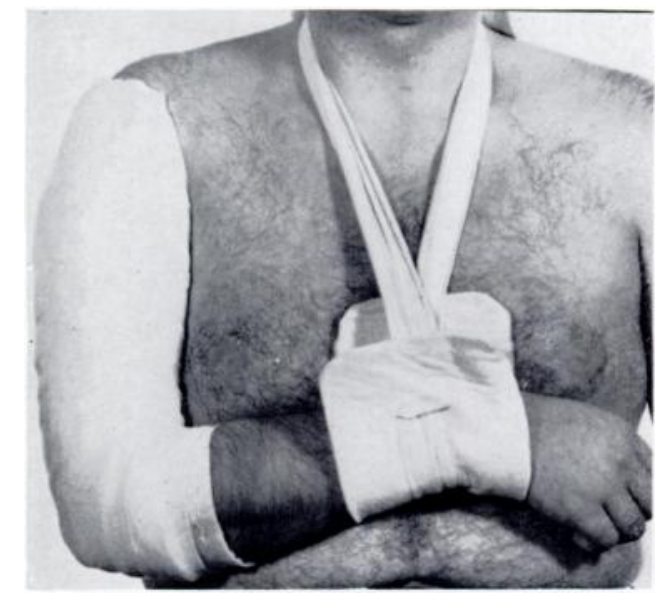

FIG. 2

The method of splintage used. same factor is probably responsible for radial nerve palsy in fractures of the middle third of the humerus where there is direct contact between the nerve and the bone in the lower part of the spiral groove (Whitson 1954). It is interesting that four of the six fractures of the middle third were of the transverse variety, as were two of the four at the junction of the middle and lowest thirds of the shaft.

Union and delayed union-Of the eighty-seven fractures treated by conservative measures twenty-three were clinically united at six weeks, thirty-four after eight weeks and thirteen at ten weeks. Six united much more slowly and took from eleven to nineteen weeks (Table IV).

TABLE III

Level of Fracture in Radial Nerve Palsy

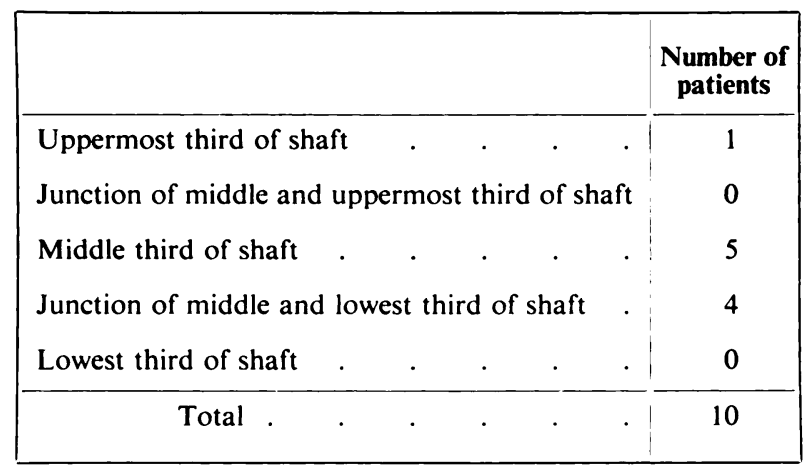

Delayed union was defined as absence of clinical union eight weeks after fracture. Ten patients fell into this group and eight of them had been treated by conservative measures. The age incidence of patients with delayed union was evenly distributed (Table V). The sites of delayed union were variable but the middle third of the bone was the commonest level where three out of five fractures were transverse (Table VI). Factors considered to be likely causes of delayed union are summarised in Table VII. 
The blood supply to the humerus is probably the most important single factor in relation to delayed union. The main nutrient artery usually enters the bone at the junction of the middle and lowest thirds, or in the lower part of the middle third (Laing 1956). The foramina

TABLE IV

Time of Union of Eighty-SEven Fractures

Treated Conservatively

\begin{tabular}{|c|c|c|c|c|}
\hline \multicolumn{4}{|c|}{ Time of union } & \multirow{2}{*}{$\begin{array}{c}\begin{array}{c}\text { Number of } \\
\text { patients }\end{array} \\
23\end{array}$} \\
\hline 6 weeks & . & & . & \\
\hline 8 weeks & . & & . & 34 \\
\hline 10 weeks & . & & . & 13 \\
\hline 11 to 15 & reeks & & . & 4 \\
\hline 16 to 20 & reeks & & . & 2 \\
\hline Delayed & nion & & . & 8 \\
\hline \multicolumn{4}{|c|}{ Inadequate information } & 3 \\
\hline & & & . & 87 \\
\hline
\end{tabular}

TABLE $V$

Age of Patients with Delayed Union

\begin{tabular}{|c|c|}
\hline $\begin{array}{c}\text { Age } \\
\text { (years) }\end{array}$ & $\begin{array}{c}\text { Number of } \\
\text { patients }\end{array}$ \\
\hline $31-40$ & 3 \\
$41-50$ & 2 \\
$51-60$ & 3 \\
$61-70$ & 2 \\
\hline
\end{tabular}

TABLE VI

Sites of DeLAyed Union

\begin{tabular}{|c|c|}
\hline Level of shaft & $\begin{array}{l}\text { Number of } \\
\text { patients }\end{array}$ \\
\hline Uppermost third & 2 \\
\hline Junction of upper and middle thirds & 1 \\
\hline Middle third $\quad . \quad . \quad . \quad . \quad$. & 5 \\
\hline Junction of middle and lowest third & 1 \\
\hline Lowest third & 1 \\
\hline
\end{tabular}

TABLE VII

The likely Causes of Delayed Union

\begin{tabular}{|c|c|c|c|c|c|}
\hline \multicolumn{5}{|c|}{ Likely causes } & \multirow{2}{*}{$\begin{array}{c}\begin{array}{c}\text { Number of } \\
\text { patients }\end{array} \\
3\end{array}$} \\
\hline Distraction or poor appos & ion & . & & . & \\
\hline Initial internal fixation . & . & . & . & . & 2 \\
\hline Probably interference with & bloo & su & 10 & le shaft & 2 \\
\hline Open injury and infection & . & . & & . & 1 \\
\hline Soft-tissue interposition & . & . & - & . & 1 \\
\hline Unknown & . & . & . & . & 1 \\
\hline
\end{tabular}

are concentrated in a small area in the region (Carroll 1963). Damage to this vessel is most likely in fractures of the middle third of the bone. It is thus significant that five examples occurred at this level, and both patients who had had internal fixation of their fractures were in this group. 
Of the ten patients with delayed union seven were treated by bone grafting and three by prolonged immobilisation of the limb. The technique of grafting consisted of internal fixation and the application of slivers of iliac crest to the fracture site. Intramedullary nails were used in five patients, one fracture was plated and one fracture was held with screws. All these operations resulted in bony union.

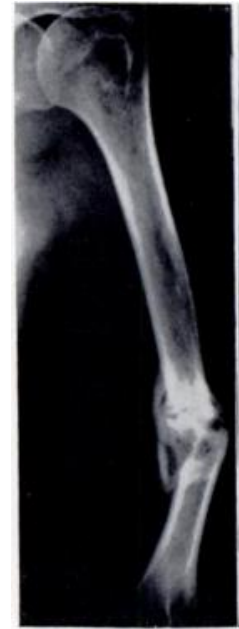

Fig. 3

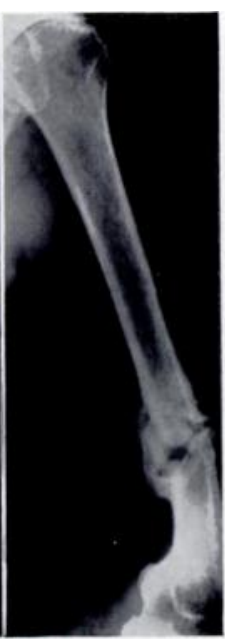

FIG. 4

Case 11. Figure 3-Radiograph of the humerus showing 35 degrees of varus. Figure 4-Radiograph showing 10 degrees of posterior angulation.

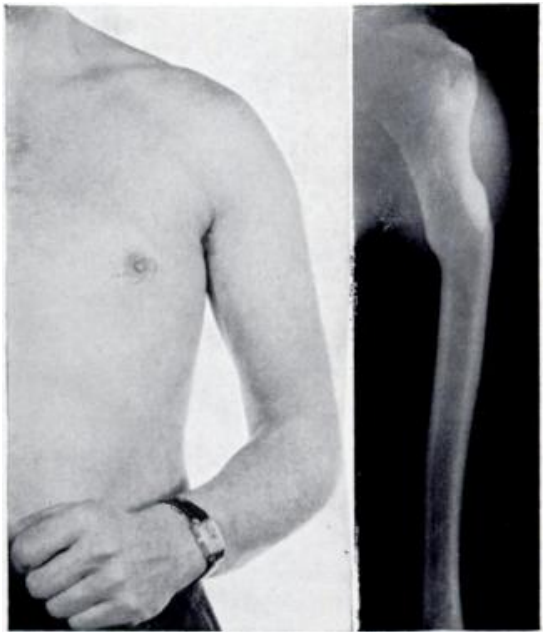

Fig. 5

Fig. 6

Case 23. Figure 5-Patient without apparent deformity of the left arm. Figure 6 -Radiograph of the humerus showing 25 degrees of varus.

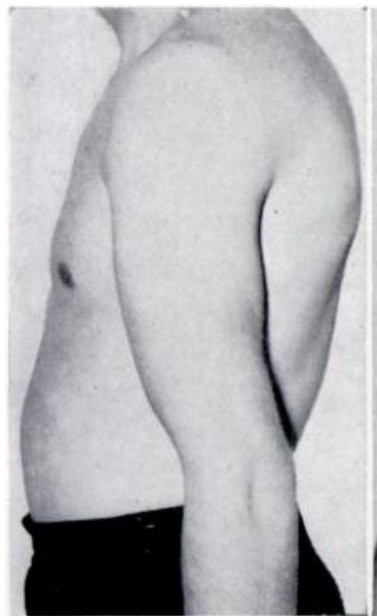

Fig. 7

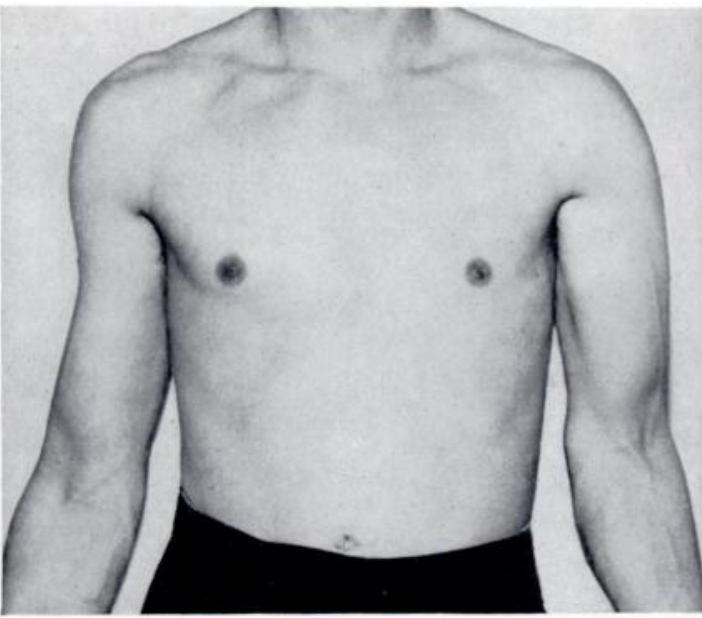

FIG. 8

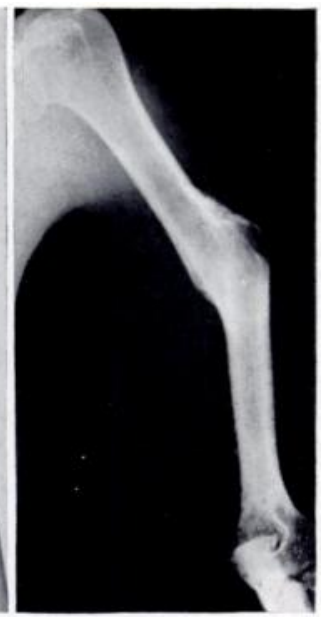

FIG. 9

Case 28. Figure 7-Patient with anterior bowing. Figure 8-Showing just perceptible varus of the left humerus. Figure 9-Radiograph of the humerus showing 35 degrees of varus.

\section{RESULTS}

In general, treatment resulted in reasonable appearance and good function. The most common radiographic deformity was varus at the fracture site (Figs. 3 and 4), irrespective of the level, and with it backward bowing was found more often than forward bowing. Valgus at the site of fracture was uncommon.

vol. 48 B, NO. 1, FEBRUARY 1966 
TABLE VIII

Correlation of Deformity and Functional Limitation

\begin{tabular}{|c|c|c|c|c|}
\hline $\begin{array}{c}\text { Case } \\
\text { number }\end{array}$ & Deformity & Fracture level & $\begin{array}{c}\text { Radiological deformity } \\
\text { (degrees) }\end{array}$ & $\begin{array}{l}\text { Functional limitation } \\
\text { (degree of movement) }\end{array}$ \\
\hline 1 & Nil & Uppermost third & 15 varus & Nil \\
\hline 2 & Nil & Lowest third & 10 varus, 6 posterior bowing & Nil \\
\hline 3 & Nil & Midshaft & 9 varus, 15 posterior bowing & Nil \\
\hline 4 & Nil & Uppermost third & Nil & Nil \\
\hline 5 & $\begin{array}{l}\text { Palpable } \\
\text { lump }\end{array}$ & Midshaft & 15 varus & Nil \\
\hline 6 & Nil & Lowest third & 10 varus, 10 posterior bowing & Nil \\
\hline 7 & Nil & Midshaft & Nil & Nil \\
\hline 8 & Nil & Midshaft & Nil (open reduction) & 30 limitation of abduction of shoulder \\
\hline 9 & Nil & Uppermost third & Nil & Nil \\
\hline 10 & Nil & Uppermost third & 10 varus & Nil \\
\hline 11 & Obvious & Lowest third & 35 varus, 10 posterior bowing & $\begin{array}{c}\text { Elbow flexion lacked } 30 . \\
\text { Extension lacked } 20 . \\
\text { Abduction of shoulder to } 120 \text { only }\end{array}$ \\
\hline 12 & Nil & Midshaft & 3 varus, 3 posterior bowing & Elbow extension lacked 15 \\
\hline 13 & Nil & Midshaft & 12 anterior bowing & Elbow extension lacked 15 \\
\hline 14 & Nil & Uppermost third & Nil & $\begin{array}{l}\text { Elbow extension lacked } 10 . \\
\text { Internal rotation of shoulder } \\
\text { two-thirds normal }\end{array}$ \\
\hline 15 & Nil & $\begin{array}{l}\text { Junction of middle } \\
\text { and uppermost thirds }\end{array}$ & 10 varus & Nil \\
\hline 16 & Nil & Lowest third & 10 valgus & $\begin{array}{l}\text { External rotation of shoulder } \\
\text { increased by one-third }\end{array}$ \\
\hline 17 & Nil & Uppermost third & 20 valgus & Nil \\
\hline 18 & Nil & Middle third & Nil & Nil \\
\hline 19 & Nil & Uppermost third & 3 valgus & Nil \\
\hline 20 & Nil & Lowest third & 2 varus & $\begin{array}{l}\text { External rotation of shoulder } \\
\text { two-thirds normal }\end{array}$ \\
\hline 21 & Nil & Midshaft & 15 varus & Nil \\
\hline 22 & Nil & Lowest third & Nil & $\begin{array}{l}\text { Elbow extension lacked } 30 \text {. } \\
\text { Terminal restriction of abduction } \\
\text { and internal rotation of shoulder }\end{array}$ \\
\hline 23 & Nil & Uppermost third & 20 posterior bowing, 35 varus & Nil \\
\hline 24 & Nil & Middle third & Nil & Nil \\
\hline 25 & Nil & Middle third & $\begin{array}{l}\text { Posterior displacement of } \\
\text { distal fragment by whole } \\
\text { diameter of shaft }\end{array}$ & Nil \\
\hline 26 & Nil & $\begin{array}{l}\text { Junction of middle } \\
\text { and uppermost thirds }\end{array}$ & 15 valgus & Nil \\
\hline 27 & Nil & Midshaft & 12 varus & Nil \\
\hline 28 & Obvious & Midshaft & 35 varus, 35 anterior bowing & Elbow extension lacked 20 \\
\hline 29 & Nil & Lowest third & Nil & Nil \\
\hline 30 & Nil & Midshaft & Nil (open reduction) & $\begin{array}{c}\text { Terminal restriction of shoulder } \\
\text { movements }\end{array}$ \\
\hline 31 & Obvious & $\begin{array}{l}\text { Junction of middle } \\
\text { and lowest thirds }\end{array}$ & 30 varus, 18 anterior bowing & Nil \\
\hline 32 & Obvious & Middle third & 20 anterior bowing & Elbow flexion and extension lacked 10 \\
\hline
\end{tabular}


None of the thirty-two patients examined had any significant disability. Despite radiological evidence of angulation the limb usually looked normal (Figs. 5 and 6). One patient with anterior bowing of 20 degrees showed an obvious bony prominence, but varus of 30 degrees or more was necessary before it became clinically apparent (Figs. 7, 8 and 9). Rotation deformity was noted in two patients only, confirming the observations of Perkins (1958) that rotation is prevented by supporting the hand on the lower part of the chest. Four patients had an obvious deformity and three were engaged in heavy work. Progressive anterior bowing despite clinical union at six weeks was seen in one patient with a transverse fracture, thus illustrating the need for protection of this type of fracture until consolidation has occurred (Perkins 1958).

Details of the correlation of deformity and functional limitation are shown in Table VIII.

\section{SUMMARY AND CONCLUSIONS}

1. It appears that fracture of the humeral shaft occurs more often in persons over fifty. This incidence corresponds with that found in a study carried out by the Pennsylvania Orthopaedic Society in 1959.

2. The middle third of the bone is the most vulnerable portion of the shaft, where transverse fracture and radial nerve palsy most commonly occur.

3. Most fractures of the shaft of the humerus are best treated by simple splintage. The degree of radiological deformity that can be accepted is far greater than in other long bones. In this group anterior bowing of 20 degrees or varus of 30 degrees was present before it became clinically obvious and even then the function of the limb was good.

4. Internal fixation is only occasionally indicated but operation on the middle third of the bone increased the chances of delayed union.

5. In the treatment of delayed union intramedullary fixation and the application of slivers of iliac bone is effective in stimulating the fracture to join.

I want to thank Mr D. R. Sweetnam for his help and encouragement; Mr P. H. Newman, Sir Reginald Watson-Jones, Mr H. Osmond-Clarke, Mr W. A. Law, Mr. O. Vaughan-Jackson, and Mr G. T. F. Braddock for permission to review their patients, and the Photographic Departments of the Middlesex Hospital and the London Hospital for their friendly assistance.

\section{REFERENCES}

Carroll, S. E. (1963): A Study of the Nutrient Foramina of the Humeral Diaphysis. Journal of Bone and Joint Surgery, 45-B, 176.

Cubbins, W. R., and SCUderi, C. S. (1933): Fractures of the Humerus. Journal of the American Medical Association, 100, 1576.

Eve, D., and Daniel, R. A., Jun. (1941): The Treatment of Fractures of the Shaft of the Humerus. Southern Medical Journal, 34, 311.

Ghormley, R. K., and Mroz, R. J. (1935): Fractures of the Humerus. End-results from Treatment. Surgery, Gynecology and Obstetrics, 60, 730.

Holstein, A., and Lewis, G. B. (1963): Fractures of the Humerus with Radial-nerve Paralysis. Journal of Bone and Joint Surgery, 45-A, 1382.

KenNedy, J. C., and Wyatt, J. K. (1957): An Evaluation of the Management of Fractures through the Middle Third of the Humerus. Canadian Journal of Surgery, 1, 26.

I.AING, P. G. (1956): The Arterial Supply of the Adult Humerus. Journal of Bone and Joint Surgery, 38-A, 1105.

O’SheA, M. C. (1936): Fractures of the Humerus. Annals of Surgery, 103, 297.

Perkins, G. (1958): Fractures and Dislocations, p. 133. University of London: The Athlone Press.

Scientific Research Committee Pennsylvania Orthopaedic Society (1959): Fresh Midshaft Fractures of the Humerus in Adults. The Pennsylvania Medical Journal, 62, 848.

Scudder, C. L. (1915): The Treatment of Fractures. Eighth edition, p. 223. Philadelphia and London: W. B. Saunders Company.

Stewart, M. J., and Hundley, J. M. (1955): Fractures of the Humerus. Journal of Bone and Joint Surgery, 37-A, 681.

Whitson, R. O. (1954): Relation of the Radial Nerve to the Shaft of the Humerus. Journal of Bone and Joint Surgery, 36-A, 85.

VOl. 48 B, NO. 1, FEBRUARY 1966 